\title{
Axillary lymph node micrometastases decrease triple-negative early breast cancer survival
}

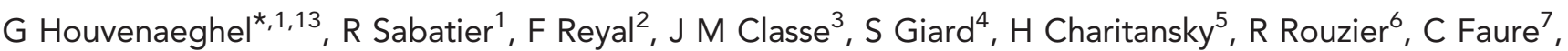 \\ J R Garbay ${ }^{8}$, E Daraï ${ }^{9}$, D Hudry ${ }^{10}$, P Gimbergues ${ }^{11}$, R Villet ${ }^{12}$ and E Lambaudie ${ }^{1,13}$ \\ ${ }^{1}$ Institut Paoli Calmettes and Centre de Recherche en Cancérologie de Marseille, INSERM U1068, CNRS U7258, 232 Bd Ste \\ Marguerite, Marseille, France; ${ }^{2}$ Institut Curie, Paris, France; Institut René Gauducheau, Site hospitalier Nord, St Herblain, France; \\ ${ }^{4}$ Centre Oscar Lambret, 3 rue Frédéric Combenal, Lille, France; ${ }^{5}$ Centre Claudius Regaud, 20-24 rue du Pont St Pierre, Toulouse, \\ France; ${ }^{6}$ Centre René Huguenin, 35 rue Dailly, Saint Cloud, France; ${ }^{7}$ Centre Léon Bérard, 28 rue Laennec, Lyon, France; \\ ${ }^{8}$ Institut Gustave Roussy, 114 rue Edouard Vaillant, Villejuif, France; ${ }^{9}$ Hôpital Tenon, 4 rue de la Chine, Paris, France; \\ ${ }^{10}$ Centre Georges François Leclerc, 1 rue du Professeur Marion, Dijon, France; ${ }^{11}$ Centre Jean Perrin, 58 rue Montalembert, \\ Clermont Ferrand, France and ${ }^{12}$ Hôpital des Diaconnesses, 18 rue du Sergent Bauchat, Paris, France
}

Background: Triple-negative breast cancers (TNBCs) are the most deadly form of breast cancer (BC) subtypes. Axillary lymph node involvement (ALNI) has been described to be prognostic in BC taken as a whole, but its prognostic value in each subtype is unclear. We explored the prognostic impact of ALNI and especially of small size axillary metastases in early TNBCs.

Methods: We analysed in this multicentre study all patients treated for early TNBC in 12 French cancer centres. We explored the correlation between clinicopathological data and ALNI, with a specific focus on the dichotomisation between macrometastases and occult metastases, which is defined as the presence of isolated tumour cells or micrometastases. The prognostic value of ALNI both in terms of disease-free survival (DFS) and overall survival (OS) was also explored.

Results: We included 1237 TNBC patients. Five-year DFS and OS were $83.7 \%$ and $88.5 \%$, respectively. The identified independent prognostic features for DFS were tumour size $>20 \mathrm{~mm}$ (hazard ratio $(H R)=1.86 ; 95 \% \mathrm{Cl}: 1.11-3.10, P=0.018$ ), lymphovascular invasion ( $\mathrm{HR}=1.69 ; 95 \% \mathrm{Cl}: 1.21-2.34, P=0.002)$ and $\mathrm{ALNI}$ both in case of macrometastases $(\mathrm{HR}=1.97 ; 95 \% \mathrm{Cl}$ : $1.38-2.81$, $P<0.0001)$ and occult metastases ( $H R=1.72 ; 95 \% \mathrm{Cl}: 1.1-2.71, P=0.019)$. DFS and OS were similar between tumours with occult metastases and macrometastases. Tumours presenting at least two pejorative features (out of ALNI, lymphovascular invasion and large tumour size) displayed a significantly poorer DFS in both the training set and validation set, independently of chemotherapy administration. Tumours with no more than one of the above-cited pejorative features had a 5 -year OS of $\geqslant 90 \%$ vs $70 \%$ for other cases $(P<0.0001)$.

Conclusions: Axillary lymph node involvement is a key prognostic feature for early TNBC when isolated tumour cells were identified in lymph nodes. This impact is independent of chemotherapy use.

Since the early 2000s gene expression profiling analyses have markedly improved breast cancer (BC) understanding by defining
BC molecular subtypes (Perou et al, 2000). Even though it represents only a partial view of $\mathrm{BC}$ biological heterogeneity, their

\footnotetext{
*Correspondence: Prof G Houvenaeghel; E-mail: g.houvenaeghel@orange.fr or houvenaeghelg@ipc.unicancer.fr

${ }^{13}$ Current address: Aix Marseille Université, Marseille, France.
}

Received 1 March 2016; revised 19 July 2016; accepted 9 August 2016; published online 29 September 2016

(c) 2016 Cancer Research UK. All rights reserved 0007 - 0920/16 
use in clinical routine practice is surrogated by the immunohistochemical assessment of hormone receptors (HRs) and HER2 expression.

Triple-negative breast cancers (TNBCs) are defined by a lack of expression of the oestrogen receptor (ER), the progesterone receptor (PR) and the absence of HER2 protein overexpression or gene amplification. They represent $15-25 \%$ of all BCs (Rakha and Ellis, 2009) and nearly 75\% of them are included in the basallike molecular subtype (Bertucci et al, 2008; Gonçalves et al, 2013). Most of the BRCA1-mutated patients develop TNBCs, and BRCA1wild-type TNBCs share molecular similarities with BRCA1mutated tumours (Robertson et al, 2012; Schmadeka et al, 2014) TNBCs display some clinical and pathologic specificities, better response rates to chemotherapy but higher rates of local relapses and poorer prognosis (Liedtke et al, 2008; Dawson et al, 2009; Foulkes et al, 2010; von Minckwitz et al, 2014). They relapse earlier than HR-positive BC with more visceral metastases (Liedtke et al, 2008; Foulkes et al, 2010). Triple-negative breast cancer management is currently based on cytotoxic chemotherapy (Jacquin et al, 2012; Mackey et al, 2013). As TNBCs demonstrate poor prognosis, efforts are needed to identify better prognostic and predictive markers to improve TNBC management.

Axillary lymph node involvement (ALNI) is known to be a major BC prognostic feature for decades (Fisher et al, 1983). Even though ALNI cannot be precisely predicted by molecular subtype classifications (Howland et al, 2013; Jones et al, 2013), its incidence seems to be lower in luminal A and higher in HER2-positive tumours (Park et al, 2012; Howland et al, 2013). It is moreover a key factor to determine the need of adjuvant chemotherapy. Assessment of a few nodes by sentinel lymph node biopsy (SLNB) can identify small size involvements such as isolated tumour cells (ITCs, $<0.2 \mathrm{~mm})$ or micrometastases $(<2 \mathrm{~mm})$. Because of improvements in pathological techniques with serial sections and immunohistochemistry (IHC) examination, a better identification of ALNI has been observed (Houvenaeghel et al, 2006).

This multicentre retrospective study aimed to identify prognostic factors in early TNBCs, with a focus on the prognostic value of the type of ALNI (occult metastases or macrometastases).

\section{MATERIALS AND METHODS}

In this retrospective, multicentre cohort study, we analysed data from women with primary TNBCs treated in 12 French centres between 1987 and 2011. This work was approved by our institutional ethics committee and Société Française de Chirurgie Oncologique.

Patients' inclusion criteria. Patients with first-line treatment for early-stage invasive $\mathrm{BC}$ without metastasis at diagnosis and with no expression of ER, PR ( $<10 \%$ of cancer cells expressing ER/PR, as defined in the French guidelines) or ERBB2 identified by IHC (score 0 or 1 ) were included. For cases with an IHC score of 2, we looked for HER2 amplification using in situ hybridisation technologies (Penault-Llorca et al, 2014). Exclusion criteria were clinical T4, bilateral disease, neoadjuvant treatment and any personal history of cancer.

Data collection. After obtaining approval from our institutional ethics committee, data were collected from individual medical files. Information gathered included demographic (age at diagnosis), clinical (cTNM), pathological (pathological subtype, tumour grade determined by the Scarff-Bloom-Richardson scoring system, pathological tumour size, presence of lymphovascular invasion (LVI) assessed by haematoxylin and eosin staining, axillary lymph node status (ITC, micrometastasis or macrometastasis)) and therapeutic data (type of surgery, adjuvant chemotherapy).
Axillary lymph node involvement assessment was performed using either SLNB after radioisotope and/or blue dye injection, or axillary lymph node dissection (ALND). We defined five groups: no lymph node metastasis ( $\mathrm{pN} 0)$, ITC $(<0.2 \mathrm{~mm}$; pNO $(\mathrm{i}+))$, micrometastases $(<2 \mathrm{~mm}$; pN1mic), isolated macrometastasis $(\geq 2 \mathrm{~mm}, \mathrm{pN} 1)$ and multiple macrometastases. Isolated tumour cells and micrometastases were assessed using serial sections and IHC examination (Houvenaeghel et al, 2006).

Survival analysis. Follow-up was measured from the date of diagnosis to the date of last news for living patients. All patients were followed up in their tertiary cancer centre or out of these centres in collaboration with their GP or local oncologist. Patients were censored when these follow-ups could not be performed with a minimal follow-up duration of 1 year. Overall survival (OS) and disease-free survival (DFS) were defined as the time from diagnosis to death from any cause or relapse.

Statistical analysis. Axillary lymph node involvement prognostic value had been adjusted to age, tumour size, pathological grade, pathological subtype and LVI. The prognostic impact of abovecited factors was assessed by the Cox regression method in univariate analysis and $P$-values were estimated with the Wald test. Only factors with a $P$-value $\leqslant 0.05$ in univariate analysis were kept for multivariate analysis.

We compared the use of adjuvant chemotherapy according to clinicopathological features including ALNI status.

We developed a score to predict DFS, according to the hazard ratios (HRs) from the Cox model in a training set representing two-thirds of our cohort $(n=825)$. We looked at the presence of $0-3$ risk factors resulting in a score of $0-3$ for each sample. We then validated this score using a validation set including the last third of our cohort $(n=412)$. We chose to split our cohort because no external cohort with appropriate clinicopathological individual data was available. To define both the training and validation sets, we classified all the cases according to their age in an ascending order: the first two patients were included in the training set and the third in the validation set. Survival analyses were performed separately in the training and validation sets.

Data concerning patients without disease progression or death at last follow-up were censored. Survival curves were estimated using the Kaplan-Meier method, and compared with the log-rank test. The Pearson's $\chi^{2}$ test was used to compare descriptive items.

All statistical tests were two sided at the $5 \%$ level of significance and analyses were performed using the SPSS 16.0 software for Windows (SPSS Inc., Chicago, IL, USA).This work was carried out according to the Strengthening the Reporting of Observational Studies in Epidemiology criteria (Vandenbroucke et al, 2007).

\section{RESULTS}

Patient's characteristics. We collected data from 1237 patients with a primary early-stage TNBC. The main patient characteristics are summarised in Table 1 . The mean age of the patients at diagnosis was 55.7 years old ( $95 \%$ CI: $55-56.4$; median $=56$ ) and the mean tumour size was $20.8 \mathrm{~mm}$ (95\% CI: 19.9-21.7; median =17).

Axillary lymph node dissection was performed for 588 patients (47.6\%) and 889 (71.9\%) underwent initial SLNB including 244 with a secondary ALND. Less than a quarter (22.8\%) of our patients presented an ALNI including 35 patients (2.8\%) with pN0(i +$), 55(4.5 \%)$ with pN1mic and 191 (15.5\%) with pN1. Out of pN1 cases, $39.8 \%$ (68 out the 171 cases with data available) had only one ALNI and $60.2 \%(103 / 171)$ had two or more ALNI. When an SLNB was performed, one or more non-sentinel metastatic lymph nodes were identified for $0.8 \%$ (5/643), $0 \%(0 / 15), 17 \%$ $(8 / 47)$ and $49.3 \%(38 / 77)$ of negative, ITC, micrometastatic and 
Table 1. Clinicopathological features

\begin{tabular}{|c|c|c|}
\hline & $N$ & $\%$ \\
\hline \multicolumn{3}{|l|}{ Age (years) } \\
\hline$\leqslant 40$ & 157 & 12.7 \\
\hline $41-50$ & 273 & 22.1 \\
\hline $51-65$ & 531 & 43 \\
\hline $66-75$ & 210 & 17 \\
\hline$>75$ & 64 & 5.2 \\
\hline \multicolumn{3}{|c|}{ Clinical tumour size (cT) } \\
\hline T0 & 213 & 17.3 \\
\hline T1 & 675 & 54.7 \\
\hline T2 & 310 & 25.1 \\
\hline T3 & 36 & 2.9 \\
\hline Unknown & 3 & \\
\hline \multicolumn{3}{|c|}{ Pathological tumour size (mm) } \\
\hline $0-5$ & 76 & 6.2 \\
\hline 5.1-10 & 190 & 15.4 \\
\hline $10.1-20$ & 549 & 44.6 \\
\hline 20.1-30 & 243 & 19.8 \\
\hline$>30$ & 172 & 14 \\
\hline \multicolumn{3}{|c|}{ Pathological subtype } \\
\hline Ductal & 1051 & 85 \\
\hline Lobular & 58 & 4.7 \\
\hline Mixed & 5 & 0.4 \\
\hline Medullary & 42 & 3.4 \\
\hline Others & 81 & 6.5 \\
\hline \multicolumn{3}{|c|}{ Tumour grade } \\
\hline 1 & 95 & 7.7 \\
\hline 2 & 291 & 23.5 \\
\hline 3 & 822 & 66.5 \\
\hline Unknown & 29 & 2.3 \\
\hline \multicolumn{3}{|l|}{ LVI } \\
\hline No & 848 & 68.6 \\
\hline Yes & 277 & 22.4 \\
\hline Unknown & 112 & 9 \\
\hline \multicolumn{3}{|c|}{ Pathological ALN status } \\
\hline pNO & 951 & 77.2 \\
\hline $\mathrm{pNO}(\mathrm{i}+)$ & 35 & 2.8 \\
\hline pN1mic & 55 & 4.5 \\
\hline pN1 & 191 & 15.5 \\
\hline \multicolumn{3}{|c|}{ Metastatic evolution } \\
\hline No & 1089 & 88 \\
\hline Yes & 148 & 12 \\
\hline \multicolumn{3}{|c|}{ Breast surgical resection } \\
\hline Conservative & 613 & 81 \\
\hline Mastectomy & 144 & 19 \\
\hline \multicolumn{3}{|l|}{ SLN biopsy } \\
\hline No & 348 & 28.1 \\
\hline Yes & 889 & 71.9 \\
\hline \multicolumn{3}{|c|}{ ALN dissection } \\
\hline No & 648 & 52.4 \\
\hline Yes & 588 & 47.6 \\
\hline \multicolumn{3}{|c|}{ Adjuvant chemotherapy } \\
\hline No & 288 & 23.3 \\
\hline Yes & 949 & 76.7 \\
\hline
\end{tabular}

macrometastatic SLNs, respectively. Most of the patients (76.7\%) received adjuvant chemotherapy.

Disease-free survival. Median follow-up was 52.8 months. We observed 190 (15.4\%) recurrences including 148 (12\%) distant metastases and $139(11.2 \%)$ deaths. Five-year DFS was $83.7 \%$ in the whole cohort.
Univariate analysis of disease-free survival showed that tumour size, LVI, high grade and ALNI were significant prognostic factors (Table 2 and Figure 1). Disease-free survival was significantly longer for $\mathrm{pN} 0$ cases $v s \quad(\mathrm{pN} 0(\mathrm{i}+) / \mathrm{pN} 1 \mathrm{mic}) \quad(P=0.003)$. No difference was observed between $\mathrm{pN} 0(\mathrm{i}+)$ and $\mathrm{pN} 1 \mathrm{mic}$ $(P=0.262)$, as well as between $\mathrm{pN} 0(\mathrm{i}+) / \mathrm{pN} 1 \mathrm{mic}$ and $\mathrm{pN} 1$ $(P=0.343)$. Disease-free survival was longer for patients presenting only one lymph node macrometastasis $(n=68)$ vs more than one macrometastasis $(n=103)(P=0.019)$.

Only tumour size $\geqslant 20 \mathrm{~mm}(\mathrm{HR}=1.86 ; 95 \mathrm{CI} \%$ : $1.11-3.09$; $P=0.018)$, LVI (HR =1.69; $95 \mathrm{CI} \%: 1.21-2.34 ; P=0.002)$ and ALNI were still significant in multivariate analysis. Axillary lymph node involvement prognostic value was observed for both $\mathrm{pN} 0(\mathrm{i}+) / \mathrm{pN} 1 \mathrm{mic}(\mathrm{HR}=1.72 ; 95 \mathrm{CI} \%: 1.1-2.71 ; P=0.019)$ and macrometastases ( $\mathrm{HR}=1.97 ; 95 \mathrm{CI} \%: 1.38-2.81 ; P<0.0001)$. After adjusting for chemotherapy administration, all these features remained significant (Supplementary Table 1). Furthermore, DFS was significantly lower for TNBCs with two or more macrometastases $(\mathrm{HR}=2.55$; 95 CI\%: $1.66-3.92 ; P<0.0001)$.

A prognostic score is able to predict DFS. To better appreciate the risk of disease recurrence, we defined a score including variables harbouring a significant prognostic value in multivariate analysis. Each of these features were noted as $0(\mathrm{pT} \leqslant 20 \mathrm{~mm}, \mathrm{pN} 0$, no LVI) or $1(\mathrm{pT}>20 \mathrm{~mm}, \mathrm{pN0}(\mathrm{i}+) / \mathrm{pN} 1 \mathrm{mic} / \mathrm{pN} 1$, presence of LVI). A score of $0-3$ was thus attributed to all patients of the training set and then validated on 412 independent samples. Clinicopathological features (age, pathological subtype, grade, LVI, tumour size, ALNI, chemotherapy administration's rate) were similar in both sets. In the training set, HR for disease recurrence were 2.5 (95 CI\%: 1.69-3.70; $P<0.0001$ ), 1.6 (95 CI\%: 1.05-2.4; $P=0.029$ ), 1.98 (95 CI\%: $1.12-3.51 ; P=0.019$ ) and 1.89 (95 CI\%: $1.19-3.01 ; P=0.007)$ for $\mathrm{pT}>20 \mathrm{~mm}, \mathrm{LVI}, \mathrm{pN} 0(\mathrm{i}+) / \mathrm{pN} 1 \mathrm{mic}$ and $\mathrm{pN} 1$, respectively.

Our prognostic score displayed a significant prognostic value both in the training and validation sets (Figure 2). This prognostic value was independent of the use of adjuvant chemotherapy for patients presenting 0,1 or 2 prognostic factors. For patients with three pejorative features, even though this was a small size group, chemotherapy improved survival $(P=0.009)$. In the validation set, 5 -year DFS was significantly longer for patients with a score of $0(87.7 \%)$ than for patients with $1(82.6 \%), 2$ (76.5\%) and $3(44.6 \%)$ pejorative features (Supplementary Table 2).

Overall survival. Five-year OS was $88.5 \%$ for the whole cohort. Univariate analysis of overall survival showed that age, tumour size, grade, LVI and ALNI were prognostic $(P<0.0001$ for all). They all kept their prognostic value in multivariate analysis: age over 75 years $(\mathrm{HR}=5.46$; $95 \mathrm{CI} \%$ : $2.50-11.9 ; P<0.0001)$, tumour size $>20 \mathrm{~mm}(\mathrm{HR}=2.05 ; 95 \mathrm{CI} \%: 1.42-2.95 ; P<0.0001)$, LVI $(\mathrm{HR}=1.76$; $95 \mathrm{CI} \%: 1.21-2.55 ; P=0.003)$, tumour grade (3 vs $1-2$; $\mathrm{HR}=1.67 ; 95 \quad \mathrm{CI} \%: \quad 1.10-2.55 ; \quad P=0.017)$ and $\mathrm{pN} 1 \quad$ ALNI $(\mathrm{HR}=1.78 ; 95 \mathrm{CI} \%: 1.15-2.74 ; P=0.009)$. No difference could be observed between $\mathrm{pN} 0(\mathrm{i}+) / \mathrm{pN} 1 \mathrm{mic}$ and $\mathrm{pN} 1$ cases $(P=0.606)$. Moreover, OS was significantly lower for TNBCs with two or more macrometastases $(\mathrm{HR}=2.01 ; 95 \mathrm{CI} \%: 1.22-3.32)$. Because chemotherapy indication is based on the presence of poor prognostic features, administration of adjuvant chemotherapy was correlated with a worst prognosis (chemotherapy vs no chemotherapy: $\mathrm{HR}=1.85$; $95 \mathrm{CI} \%$ : 1.12-3.06; $P=0.016$ ). After adjusting for chemotherapy administration, all clinicopathological features remained significant (Supplementary Table 1).

We then assessed the capacity of our prognostic score to predict OS. Overall survival was significantly different across the four groups $(P<0.0001)$ (Figure 3$)$. Patients with a score of $0-1$ had a 5 -year OS of $93.5 \%$ and $90.9 \%$, respectively, whereas patients with a score $\geqslant 2$ had significantly poorer 5 -year OS of $74.6 \%$ and $68.8 \%$, respectively (Supplementary Table 3). It is worth noting that 
OS was influenced by adjuvant chemotherapy administration, with a longer survival for patients presenting $0-2$ pejorative prognostic features when they receive chemotherapy $(P=0.004)$. Despite a few patients with a score of 3 did not receive chemotherapy, systemic chemotherapy also significantly improved survival in this subset $(P=0.013)$.

\section{Table 2. Disease-free survival and overall survival results: univariate and multivariate analysis}

\begin{tabular}{|c|c|c|c|c|c|c|}
\hline & \multicolumn{3}{|c|}{ Disease-free survival } & \multicolumn{3}{|c|}{ Overall survival } \\
\hline & $\begin{array}{c}\text { Log rank } \\
P \text {-value }\end{array}$ & $\begin{array}{c}\text { Cox }{ }^{a} \\
P \text {-value }\end{array}$ & $\mathrm{HR}(95 \% \mathrm{Cl})$ & $\begin{array}{l}\text { Log rank } \\
P \text {-value }\end{array}$ & $\begin{array}{c}\text { Cox }{ }^{a} \\
P \text {-value }\end{array}$ & $\mathrm{HR}(95 \% \mathrm{Cl})$ \\
\hline $\begin{array}{l}\text { Age (years) } \\
\leqslant 40 \\
41-75 \\
>75\end{array}$ & 0.073 & & & $<0.0001$ & $\begin{array}{c}0.083 \\
<0.0001\end{array}$ & $\begin{array}{c}1 \\
1.62(0.94-2.81) \\
5.46(2.50-11.9)\end{array}$ \\
\hline $\begin{array}{l}\text { pT }(\mathrm{mm}) \\
0-10 \\
>20\end{array}$ & $<0.0001$ & $<0.0001$ & $\begin{array}{c}1 \\
1.96(1.44-2.66)\end{array}$ & $<0.0001$ & $<0.0001$ & $\begin{array}{c}1 \\
2.05(1.42-2.95)\end{array}$ \\
\hline $\begin{array}{l}\text { LVI } \\
\text { Yes vs no }\end{array}$ & $<0.0001$ & 0.001 & $1.68(1.22-2.32)$ & $<0.0001$ & 0.003 & $1.76(1.21-2.55)$ \\
\hline $\begin{array}{l}\mathrm{pN} \\
\mathrm{pNO} \\
\mathrm{i}+, \mathrm{mic} \\
\text { Macro }\end{array}$ & $<0.0001$ & $\begin{array}{c}0.019 \\
<0.0001\end{array}$ & $\begin{array}{l}\quad 1 \\
1.72(1.1-2.71) \\
1.97(1.38-2.81)\end{array}$ & $<0.0001$ & $\begin{array}{l}0.121 \\
0.009\end{array}$ & $\begin{array}{c}1 \\
1.52(0.89-2.59) \\
1.78(1.15-2.74)\end{array}$ \\
\hline $\begin{array}{l}\text { Grade } \\
3 \text { vs } 1 \text { or } 2\end{array}$ & 0.047 & 0.169 & & 0.018 & 0.017 & $1.67(1.10-2.55)$ \\
\hline $\begin{array}{l}\text { Chemotherapy } \\
\text { No vs yes }\end{array}$ & 0.622 & & & 0.744 & & \\
\hline Pathological subtype & 0.433 & & & 0.565 & & \\
\hline $\begin{array}{l}\text { Abbreviations: } 95 \% \mathrm{Cl}=9 \\
\text { tumour size. } \\
\text { a Wald test. }\end{array}$ & nce interval; $\vdash$ & io; $L V I=\operatorname{lym}$ & ar invasion; $N=$ num & atients; $\mathrm{pN}=\mathrm{p}$ & lymph onde & nent; $\mathrm{pT}=$ pathologic \\
\hline
\end{tabular}
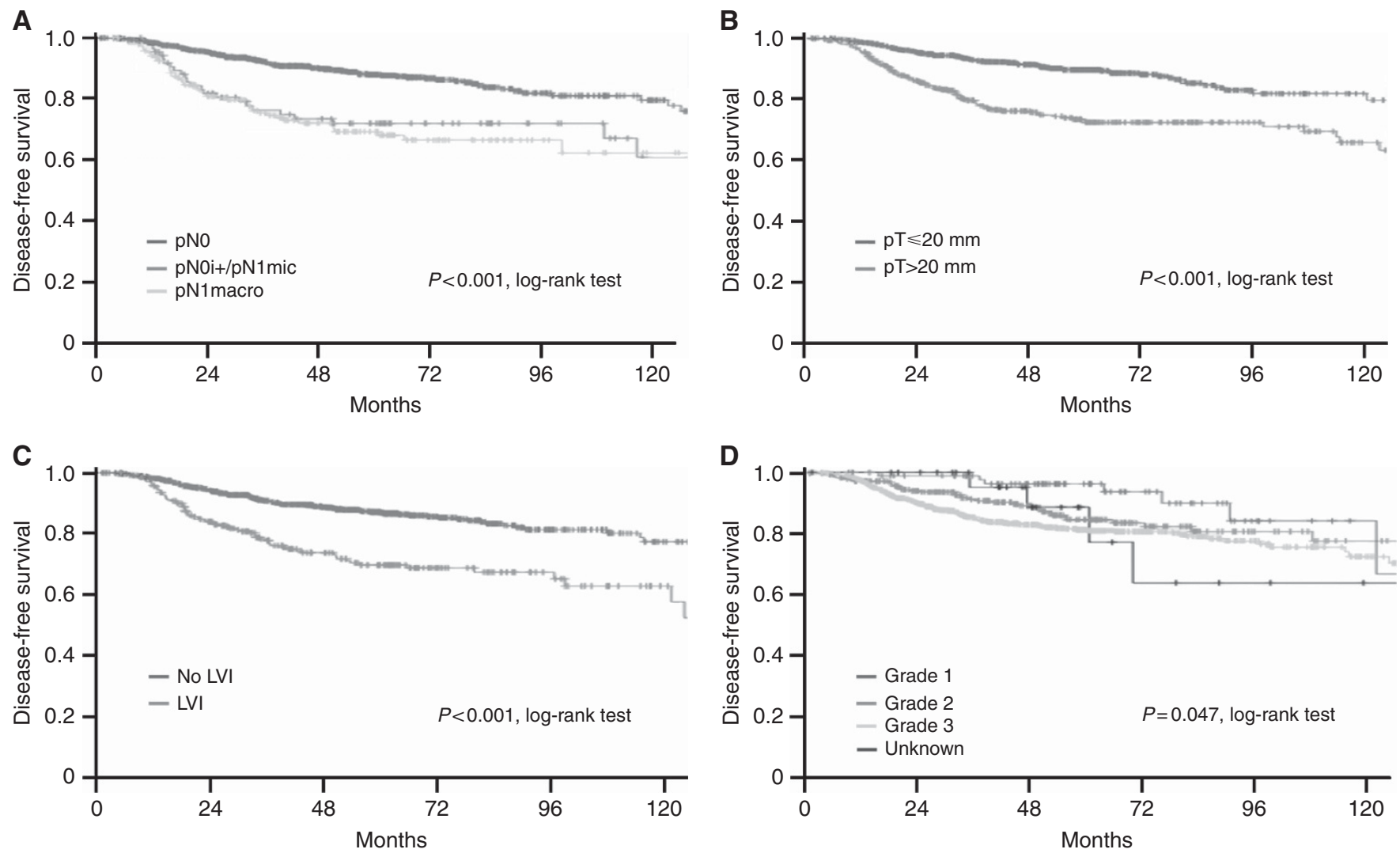

Figure 1. Disease-free survival according to prognostic factors. (A) axillary lymph node status, (B) tumour size, (C) presence of lymphovascular invasion (LVI), (D) tumour grade. 
Clinicopathological features associated with ALNI. As LN involvement was an independent prognostic feature in our cohort, we decided to look for other pathological factors able to predict ALNI of any size (Table 3). Multivariate analysis showed that pathological features, such as tumour size (odds ratio $(\mathrm{OR})=1.97$ for tumours 11-20 mm (95 CI\%: 1.1-3.49; $P=0.021$ ); OR $=4.29$ for tumours $>20 \mathrm{~mm}$ (95 CI\%: 2.43-7.56; $P<0.0001$ ) and LVI $(\mathrm{OR}=4.17$; $[3.5-5.8] ; P<0.0001)$, correlated with ALNI. Comparison between ALN status, with distinction between $\mathrm{pN} 0, \mathrm{pNO}(\mathrm{i}+)$, $\mathrm{pN} 1 \mathrm{mi}$ and $\mathrm{pN} 1$, and the other pathological features is presented in Supplementary Table 4. Large tumour size, high grade and presence of LVI were more frequent in cases presenting ALNI. No significant difference could be identified between $\mathrm{pNO}(\mathrm{i}+)$ and pN1mic tumours.

ALNI is used to prescribe systemic chemotherapy. As recommended by BC guidelines (Saint Gallen 2015), $\leqslant 3$ ALNI did not always require the use of chemotherapy. To determine if in clinical practice the choice to use chemotherapy was based more on tumour features than on LN status, we explored the clinicopathological features that correlated with chemotherapy administration. Predictive characteristics of chemotherapy use identified by univariate analysis were age, tumour size, LVI, tumour grade, pathological subtype and ALNI (Supplementary Table 5). All these features remained significant in multivariate analysis. With regard to ALNI, pN1 $(P=0.002)$ and pN1mic $(P=0.004)$ were significantly associated with chemotherapy use, whereas the presence of ITC was not $(P=0.09)$.

\section{DISCUSSION}

This study has included the largest cohort of TNBC with ALNI details ever published. Occult ALNI display an independent prognostic value that seems to be equal to that of the presence of one macrometastasis. Axillary lymph node involvement is moreover independent of all other usual clinicopathological features.

This study is the first work evaluating the prognostic value of the type of ALNI in early TNBC treated by front-line surgery. Some authors described that TNBC showed a significantly lower risk of ALNI than HR-positive or HER2-positive tumours (HolmRasmussen et al, 2015). We have previously explored the prognostic value of microscopic ALNI for 8001 BC patients with SLNB without molecular selection (Houvenaeghel et al, 2006). Only macrometastases were correlated with prognosis with an intermediate outcome for cases with one lesion and a poor outcome for tumours with at least two macrometastases. Occult metastases were not predictive of disease recurrence and death.

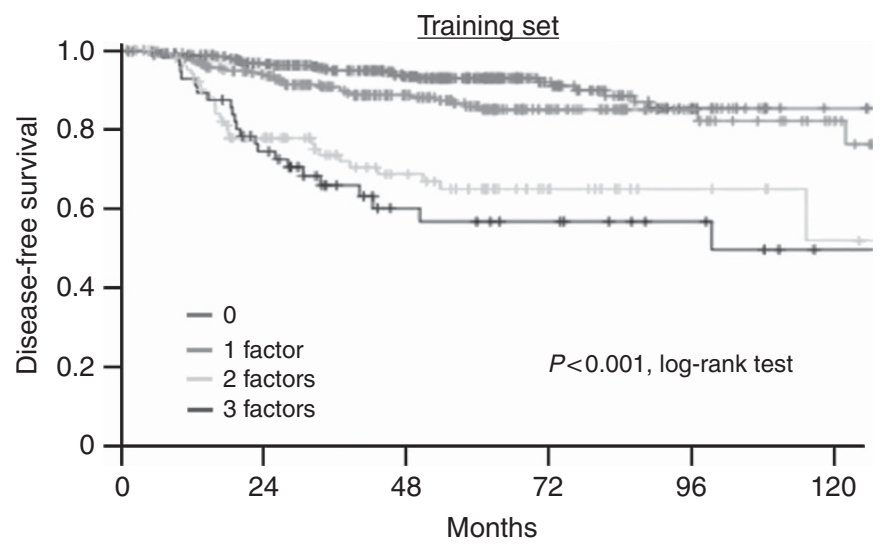

However, published series showed discordant results. Six-year OS and 5-year DFS were similar between $\mathrm{pN} 0$ and $\mathrm{pN} 0(\mathrm{i}+) / \mathrm{pN} 1 \mathrm{mic}$ patients (Hansen et al, 2009; Maaskant-Braat et al, 2011). Others showed discrepant results with a poorer 10-year OS for patients with pN0(i+)/pN1mic ALNI (Truong et al, 2010; Weaver et al, 2011). Such a discrepancy in studies including all molecular subtypes may be explained by the fact that occult metastases may display heterogeneous prognostic values across molecular subtypes.

This study is the first to define the prognostic value of occult ALNI for TNBC. Axillary lymph node involvement was less frequent in TNBC compared with that in HER2-positive BC (Reyal et al, 2011; Houvenaeghel et al, 2014). In BC $\leqslant 30 \mathrm{~mm}$, ALNI was $\leqslant 30 \%$ for TNBC $v s \geqslant 50 \%$ for the other subtypes. In the current study, ALNI is correlated independently with tumour size $>11 \mathrm{~mm}$ and LVI. We moreover show that occult metastases are independently associated with OS and DFS. They increase risks of disease recurrence and mortality by similar HR compared with the presence of one macrometastasis. However, this lack of statistical difference in prognosis may simply be a power issue owing to the relative small size of the ITC/mic + group $(n=90)$. We are the first group to dichotomise TNBC patients with the presence of one or more macroscopic ALNI. Disease-free survival and OS are significantly lower for TNBCs with two or more LN macrometastases $(\mathrm{HR}=2.55$ and 2.01, respectively).

The other independent prognostic features identified were tumour size and LVI. Tumour size has been described to be correlated with BC prognostic for decades (Fisher et al, 1969; Carter et al, 1989; Neville et al, 1992). Its prognostic impact remains significant within each molecular subtype (Chia et al, 2004). The presence of LVI has

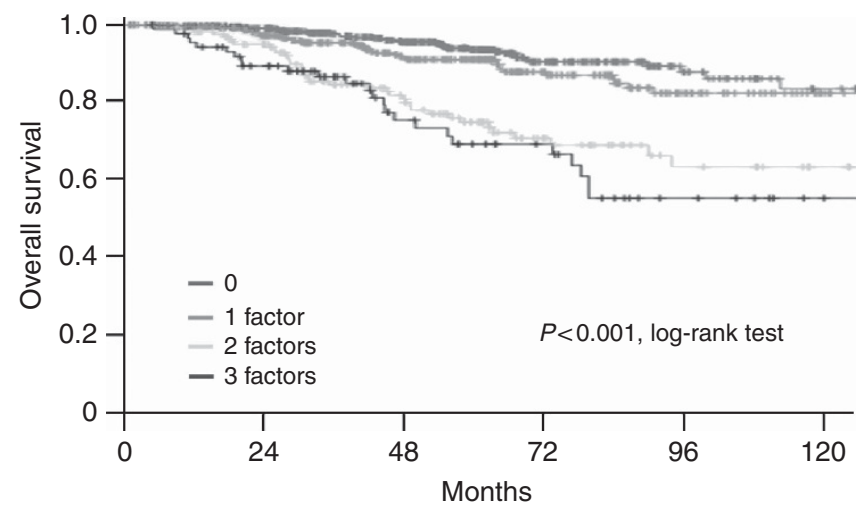

Figure 3. Overall survival according to prognostic score.

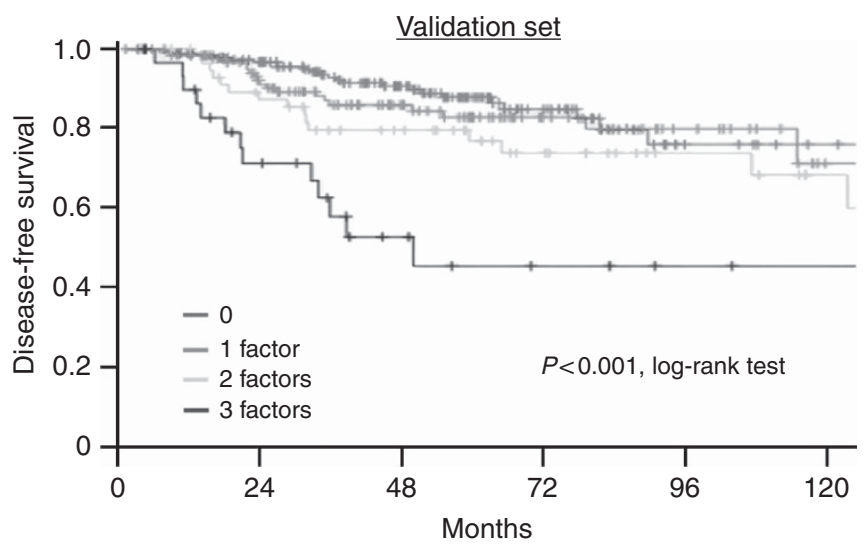

Figure 2. Disease-free survival according to prognostic score (0 to 3 factors) for Training set and Validation set. 
Table 3. Clinicopathological features predictive of axillary lymph node involvement

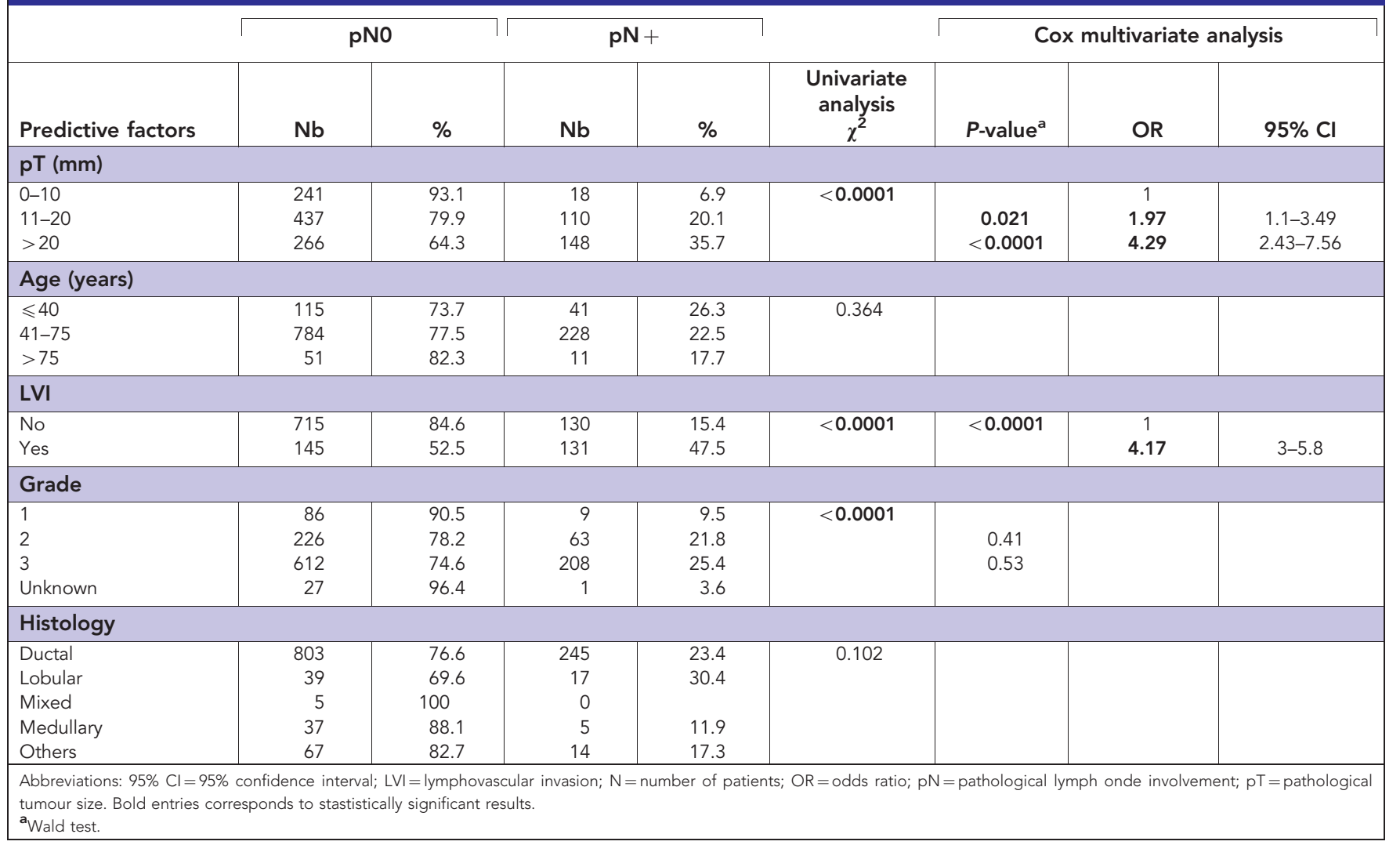

also been described to be prognostic in BC for decades. LVI decreased DFS after adjustment for tumour size and ALNI (Bettelheim et al, 1984). LVI is known to be a major and independent prognostic feature in TNBCs with a three-fold increase in the risk of distant metastasis (Sabatier et al, 2011). In this study, we show that despite this prognostic value of LVI, ALNI and the type of ALNI are prognostic.

These results may lead to changes in systemic management of TNBCs. The choice to give adjuvant chemotherapy is currently mainly based on tumour features. However, in this study, we show that clinicians more often chose to administrate chemotherapy in patients with ALNI, independently of the size of these metastases and of tumour size and LVI. This observation has already been made by others who showed that BC patients with occult LNI received more chemotherapy than node-negative patients (Maaskant-Braat et al, 2011; Houvenaeghel et al, 2014).

To better identify patients with poor prognosis, we defined a prognostic score on a training set and validated it on the remaining patients. This score can be applied to all TNBCs. It is able to distinguish patients with significantly different prognoses, notably different OS. Patients with none or one pejorative feature had a 5 -year OS of $\geqslant 90 \%$, whereas it was close to $70 \%$ for cases with two or three pejorative criteria. Further studies are thus warranted to decrease systemic therapy use for low score patients and/or to increase treatments for high score ones.

In this study, a complementary ALND were performed for patients with SN involved by ITC or micrometastases. In some centres, complementary ALND is not systematically performed since the reports of the results of the ACOSOG Z0011 and IBCSG 23-01 trials, but without consideration of molecular subtyping (Giuliano et al, 2010; Galimberti et al, 2013). By omitting to perform this complementary resection, $10-18 \%$ of patients with SN involved by ITC or micrometastases have non-sentinel node macrometastases that remain unknown. This should lead clinicians to make the choice to use systemic chemotherapy for TNBC patients presenting ITC or micrometastases as the only poor prognostic feature (Aigner et al, 2013).

This work has some limitations. The first one is its retrospective design. However, this can be counterbalanced by the fact it includes a large sample size. Adjuvant systemic therapies had not been standardised and chemotherapy details were not available for analysis. It is worth noting that ALND was performed for most of the patients in the early 1990s, whereas it is currently performed only for SLN-positive cases. Some ALNI could have been missed because of SLN-false-negative results (Layeequr Rahman et al, 2015). Finally, we chose to not analyse radiotherapy data here as they were missing for a large part of our cohort.

In conclusion, this study is the first to monitor the prognostic value of the type of lymph node involved in a large TNBC cohort. Axillary lymph node involvement is a key prognostic feature involved independently of its size. Occult metastases thus display a significant prognostic value in the TNBC population independent of other prognostic factors such as tumour size and LVI. Axillary lymph node involvement diagnosis thus seems to be crucial for TNBC, with the need to look for ITC and micrometastases by serial sections and IHC examination. This need may be importatn for small size tumours without other criteria of chemotherapy administration as it is for ER-positive cancers (Parmigiani et al, 1999). Prospective studies deserve to be performed to assess adjuvant chemotherapy benefits for early TNBC with occult ALNI.

\section{ACKNOWLEDGEMENTS}

This work was supported by SIRIC (INCa-DGOS-Inserm 6038 grant), Institut Paoli-Calmettes and Société Française de Chirurgie Oncologique. 


\section{CONFLICT OF INTEREST}

The authors declare no conflict of interest.

\section{REFERENCES}

Aigner J, Smetanay K, Hof H, Sinn H-P, Sohn C, Schneeweiss A, Marmé F (2013) Omission of axillary dissection according to ACOSOG Z0011: impact on adjuvant treatment recommendations. Ann Surg Oncol 20: 1538-1544.

Bertucci F, Finetti P, Cervera N, Esterni B, Hermitte F, Viens P, Birnbaum D (2008) How basal are triple-negative breast cancers? Int J Cancer 123: 236-240.

Bettelheim R, Penman HG, Thornton-Jones H, Neville AM (1984) Prognostic significance of peritumoral vascular invasion in breast cancer. $\mathrm{Br} J$ Cancer 50: 771-777.

Carter CL, Allen C, Henson DE (1989) Relation of tumor size, lymph node status, and survival in 24740 breast cancer cases. Cancer 63: 181-187.

Chia SK, Speers CH, Bryce CJ, Hayes MM, Olivotto IA (2004) Ten-year outcomes in a population-based cohort of node-negative, lymphatic, and vascular invasion-negative early breast cancers without adjuvant systemic therapies. J Clin Oncol 22: 1630-1637.

Dawson SJ, Provenzano E, Caldas C (2009) Triple negative breast cancers: clinical and prognostic implications. Eur J Cancer 45: 27-40.

Fisher B, Bauer M, Wickerham DL, Redmond CK, Fisher ER, Cruz AB, Foster R, Gardner B, Lerner H, Margolese R (1983) Relation of number of positive axillary nodes to the prognosis of patients with primary breast cancer. An NSABP update. Cancer 52: 1551-1557.

Fisher B, Slack NH, Bross ID (1969) Cancer of the breast: size of neoplasm and prognosis. Cancer 24: 1071-1080.

Foulkes WD, Smith IE, Reis-Filho JS (2010) Triple-negative breast cancer. N Engl J Med 363: 1938-1948.

Galimberti V, Cole BF, Zurrida S, Viale G, Luini A, Veronesi P, Baratella P, Chifu C, Sargenti M, Intra M, Gentilini O, Mastropasqua MG, Mazzarol G, Massarut S, Garbay J-R, Zgajnar J, Galatius H, Recalcati A, Littlejohn D, Bamert M, Colleoni M, Price KN, Regan MM, Goldhirsch A, Coates AS, Gelber RD, Veronesi U (2013) Axillary dissection vs no axillary dissection in patients with sentinel-node micrometastases (IBCSG 23-01): a phase 3 randomised controlled trial. Lancet Oncol 14: 297-305.

Giuliano AE, McCall L, Beitsch P, Whitworth PW, Blumencranz P, Leitch AM, Saha S, Hunt KK, Morrow M, Ballman K (2010) Locoregional recurrence after sentinel lymph node dissection with or without axillary dissection in patients with sentinel lymph node metastases: the American College of Surgeons Oncology Group Z0011 randomized trial. Ann Surg 252: $426-432-433$.

Gonçalves A, Sabatier R, Charafe-Jauffret E, Gilabert M, Provansal M, Tarpin C, Extra J-M, Viens P, Bertucci F (2013) [Triple-negative breast cancer: histoclinical and molecular features, therapeutic management and perspectives]. Bull Cancer 100: 453-464.

Hansen NM, Grube B, Ye X, Turner RR, Brenner RJ, Sim M-S, Giuliano AE (2009) Impact of micrometastases in the sentinel node of patients with invasive breast cancer. J Clin Oncol 27: 4679-4684.

Holm-Rasmussen EV, Jensen M-B, Balslev E, Kroman N, Tvedskov TF (2015) Reduced risk of axillary lymphatic spread in triple-negative breast cancer. Breast Cancer Res Treat 149: 229-236.

Houvenaeghel G, Classe J-M, Garbay J-R, Giard S, Cohen M, Faure C, Hélène C, Belichard C, Uzan S, Hudry D, Azuar P, Villet R, Penault Llorca F, Tunon de Lara C, Goncalves A, Esterni B. Groupe des Chirurgiens de la Federation des Centres de Lutte Contre le Cancer (2014) Prognostic value of isolated tumor cells and micrometastases of lymph nodes in early-stage breast cancer: a French sentinel node multicenter cohort study. Breast Edinb Scotl 23: 561-566.

Houvenaeghel G, Nos C, Mignotte H, Classe JM, Giard S, Rouanet P, Lorca FP, Jacquemier J, Bardou VJ. Groupe des Chirurgiens de la Federation des Centres de Lutte Contre le Cancer (2006) Micrometastases in sentinel lymph node in a multicentric study: predictive factors of nonsentinel lymph node involvement - Groupe des Chirurgiens de la Federation des Centres de Lutte Contre le Cancer. J Clin Oncol 24: 1814-1822.

Howland NK, Driver TD, Sedrak MP, Wen X, Dong W, Hatch S, Eltorky MA, Chao C (2013) Lymph node involvement in immunohistochemistry-based molecular classifications of breast cancer. J Surg Res 185: 697-703.
Jacquin J-P, Jones S, Magné N, Chapelle C, Ellis P, Janni W, Mavroudis D, Martín M, Laporte S (2012) Docetaxel-containing adjuvant chemotherapy in patients with early stage breast cancer. Consistency of effect independent of nodal and biomarker status: a meta-analysis of 14 randomized clinical trials. Breast Cancer Res Treat 134: 903-913.

Jones T, Neboori H, Wu H, Yang Q, Haffty BG, Evans S, Higgins S, Moran MS (2013) Are breast cancer subtypes prognostic for nodal involvement and associated with clinicopathologic features at presentation in early-stage breast cancer? Ann Surg Oncol 20: 2866-2872.

Layeequr Rahman R, Crawford SL, Siwawa P (2015) Management of axilla in breast cancer - the saga continues. Breast 24: 343-353.

Liedtke C, Mazouni C, Hess KR, André F, Tordai A, Mejia JA, Symmans WF, Gonzalez-Angulo AM, Hennessy B, Green M, Cristofanilli M, Hortobagyi GN, Pusztai L (2008) Response to neoadjuvant therapy and long-term survival in patients with triple-negative breast cancer. J Clin Oncol 26: 1275-1281.

Maaskant-Braat AJ, van de Poll-Franse LV, Voogd AC, Coebergh JWW, Roumen RM, Nolthenius-Puylaert MCT, Nieuwenhuijzen GA (2011) Sentinel node micrometastases in breast cancer do not affect prognosis: a population-based study. Breast Cancer Res Treat 127: 195-203.

Mackey JR, Martin M, Pienkowski T, Rolski J, Guastalla J-P, Sami A, Glaspy J, Juhos E, Wardley A, Fornander T, Hainsworth J, Coleman R, Modiano MR, Vinholes J, Pinter T, Rodríguez-Lescure A, Colwell B, Whitlock P, Provencher L, Laing K, Walde D, Price C, Hugh JC, Childs BH, Bassi K, Lindsay M-A, Wilson V, Rupin M, Houé V, Vogel C. TRIO/BCIRG 001 investigators (2013) Adjuvant docetaxel, doxorubicin, and cyclophosphamide in node-positive breast cancer: 10-year follow-up of the phase 3 randomised BCIRG 001 trial. Lancet Oncol 14: 72-80.

von Minckwitz G, Schneeweiss A, Loibl S, Salat C, Denkert C, Rezai M, Blohmer JU, Jackisch C, Paepke S, Gerber B, Zahm DM, Kümmel S, Eidtmann H, Klare P, Huober J, Costa S, Tesch H, Hanusch C, Hilfrich J, Khandan F, Fasching PA, Sinn BV, Engels K, Mehta K, Nekljudova V, Untch M (2014) Neoadjuvant carboplatin in patients with triple-negative and HER2-positive early breast cancer (GeparSixto; GBG 66): a randomised phase 2 trial. Lancet Oncol 15: 747-756.

Neville AM, Bettelheim R, Gelber RD, Säve-Söderbergh J, Davis BW, Reed R, Torhorst J, Golouh R, Peterson HF, Price KN (1992) Factors predicting treatment responsiveness and prognosis in node-negative breast cancer. The International (Ludwig) Breast Cancer Study Group. J Clin Oncol 10: 696-705.

Park S, Koo JS, Kim MS, Park HS, Lee JS, Lee JS, Kim SI, Park B-W (2012) Characteristics and outcomes according to molecular subtypes of breast cancer as classified by a panel of four biomarkers using immunohistochemistry. Breast 21: 50-57.

Parmigiani G, Berry DA, Winer EP, Tebaldi C, Iglehart JD, Prosnitz LR (1999) Is axillary lymph node dissection indicated for early-stage breast cancer? A decision analysis. J Clin Oncol 17: 1465-1473.

Penault-Llorca F, Vincent-Salomon A, MacGrogan G, Roger P, Treilleux I, Valent A, Mathieu M-C, Antoine M, Becette V, Bor C, Brabencova E, Charafe-Jauffret E, Chenard M-P, Dauplat M-M, Delrée P, Devouassoux M, Fiche M, Fondrevelle M-E, Fridman V, Garbar C, Genin P, Ghnassia J-P, Haudebourg J, Laberge-Le Couteulx S, Loussouarn D, Maran-Gonzalez A, Marcy M, Michenet P, Poulet B, Sagan C, Trassard M, Verriele V, Arnould L, Lacroix-Triki M (2014) Mise à jour 2014 des recommandations du GEFPICS pour l'évaluation du statut HER2 dans les cancers du sein en France. Ann Pathol 34: 352-365.

Perou CM, Sørlie T, Eisen MB, van de Rijn M, Jeffrey SS, Rees CA, Pollack JR, Ross DT, Johnsen H, Akslen LA, Fluge O, Pergamenschikov A, Williams C, Zhu SX, Lønning PE, Børresen-Dale AL, Brown PO, Botstein D (2000) Molecular portraits of human breast tumours. Nature 406: $747-752$

Rakha EA, Ellis IO (2009) Triple-negative/basal-like breast cancer: review. Pathology (Phila) 41: 40-47.

Reyal F, Rouzier R, Depont-Hazelzet B, Bollet MA, Pierga J-Y, Alran S, Salmon RJ, Fourchotte V, Vincent-Salomon A, Sastre-Garau X, Antoine M, Uzan S, Sigal-Zafrani B, De Rycke Y (2011) The molecular subtype classification is a determinant of sentinel node positivity in early breast carcinoma. PloS One 6 : e20297.

Robertson L, Hanson H, Seal S, Warren-Perry M, Hughes D, Howell I, Turnbull C, Houlston R, Shanley S, Butler S, Evans DG, Ross G, Eccles D, Tutt A, Rahman N. TNT Trial TMG, BCSC (UK) (2012) BRCA1 testing should be offered to individuals with triple-negative breast cancer diagnosed below 50 years. Br J Cancer 106: 1234-1238. 
Sabatier R, Jacquemier J, Bertucci F, Esterni B, Finetti P, Azario F, Birnbaum D, Viens P, Gonçalves A, Extra J-M (2011) Peritumoural vascular invasion: a major determinant of triple-negative breast cancer outcome. Eur J Cancer Oxf Engl 1990 47: 1537-1545.

Schmadeka R, Harmon BE, Singh M (2014) Triple-negative breast carcinoma: current and emerging concepts. Am J Clin Pathol 141: 462-477.

Truong PT, Lesperance M, Li KH, MacFarlane R, Speers CH, Chia S (2010) Micrometastatic node-positive breast cancer: long-term outcomes and identification of high-risk subsets in a large population-based series. Ann Surg Oncol 17: 2138-2146.

Vandenbroucke JP, von Elm E, Altman DG, Gøtzsche PC, Mulrow CD, Pocock SJ, Poole C, Schlesselman JJ, Egger M. STROBE Initiative (2007)
Strengthening the Reporting of Observational Studies in Epidemiology (STROBE): explanation and elaboration. PLoS Med 4: e297.

Weaver DL, Ashikaga T, Krag DN, Skelly JM, Anderson SJ, Harlow SP, Julian TB, Mamounas EP, Wolmark N (2011) Effect of occult metastases on survival in node-negative breast cancer. N Engl J Med 364: 412-421.

This work is published under the standard license to publish agreement. After 12 months the work will become freely available and the license terms will switch to a Creative Commons AttributionNonCommercial-Share Alike 4.0 Unported License.

Supplementary Information accompanies this paper on British Journal of Cancer website (http://www.nature.com/bjc) 